\title{
Soutien de l'âme pour personnes sans âme?
}

\author{
Christina Aus der Au
}

Prof. de théologie, membre de la rédaction Ethique

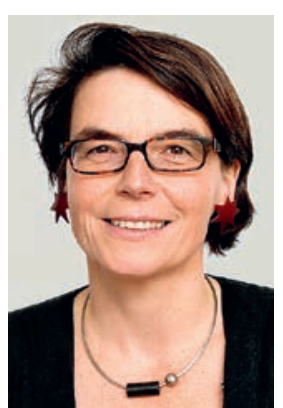

Lorsque je n'ai rien à faire, j'aime passer un quart d'heure à explorer Facebook. Les citations amusantes me font sourire et ici ou là, j'aime une publication intéressante. J'y trouve aussi souvent des remarques et des pistes de réflexion captivantes. Il y a peu, j’ai par exemple lu sur la page d'un représentant des libres penseurs: «Très bonne conférence l'après-midi sur le ¿Soutien de l'âme pour personnes sans âme»".

Voilà une présentation à laquelle j'aurais volontiers assisté aussi. Que sont des gens sans âme? Des gens inanimés au sens théologique du terme? Des zombies? Des matérialistes purs et durs? Et en quoi consiste alors le soutien de l'âme? De quoi s'occupe-t-on? Du cerveau? Du corps? De la vie ici et maintenant? Est-ce fondamentalement si différent du soutien de l'âme pour les personnes qui en ont une?

D'ailleurs, n'est-ce pas un raccourci de rattacher ainsi l'âme à une foi religieuse? Cela signifie en effet l'identifier à la vie après la mort. Je le dis de manière tout à fait autocritique, ma propre confrérie (religieuse et théologique) a, dans son histoire, attaché une grande importance au salut éternel de l'âme, aux feux de l'Enfer et au Paradis. Les athées et les libres penseuses peuvent donc tout à fait penser que ceux qui ne croient pas en Dieu et à la vie après la mort n'ont pas besoin d'une âme, même si je me doute bien que ce titre de conférence se veut avant tout provocateur.

Mais il a atteint son but, il m'a fait réfléchir. Qu'est-ce qu'une âme? Le noyau immortel de l'homme tombé du ciel, comme l'enseignait le philosophe grec Platon? Ou simplement le principe d'organisation du corps, comme le pensait Aristote, son élève aux thèses duquel il est aujourd'hui plus facile d'adhérer? Ces deux axes sont également présents dans la tradition chrétienne. Alors que l'Ancien Testament imagine l'âme comme le souffle de Dieu, qui donne vie au corps des hommes et des animaux, le christianisme s'est souvent rallié à René Descartes dans la lignée de Platon: l'âme est le pendant entièrement spirituel et immortel du corps.

On peut donc envisager l'âme de multiples façons, avec ou sans corps, avec ou sans les cieux. Mais elle ne disparaît pas complètement, ne serait-ce que parce qu'elle est trop présente dans le langage courant. Je pars la mort dans l'âme, je m'investis corps et âme, j'ai le vague à l'âme, j'ai trouvé mon âme sœur, j'admire la grandeur d'âme de quelqu'un, j'erre comme une âme en peine, je trouve une âme charitable pour m'aider. Tout comme un lieu sans âme, une personne sans âme a quelque chose d'inquiétant. Et même si les médecins n'ont trouvé le siège de l'âme ni dans le cerveau ni dans le cœur, ils ont sans aucun doute dû s'accommoder de la psyché. A Zurich, la «Clinique de psychiatrie de consultation et de psychosomatique» est rattachée à la psychiatrie, tandis qu'à Bâle, la psychosomatique est un service particulier de la médecine interne. Il y a certainement aussi des libres penseuses et penseurs souffrant de stress, de névrodermite ou de troubles anxieux. Ils ne peuvent alors faire l'impasse sur la psyché. Ce que doit leur apporter la psychosomatique peut-il alors être qualifié de soutien de l'âme? Ou s'agit-il plutôt de soutien de la psyché? Du coup, je m'interroge: est-ce un hasard si les jeunes s'insultent en se traitant de psychopathe alors qu'il n'y a pas d'équivalent avec âme? Peut-être la psyché n'estelle ici finalement pas tout à fait synonyme de l'âme. Il est également intéressant de noter que les centres universitaires de Zurich comme de Bâle évoquent des causes psychiques. Pour pouvoir provoquer des troubles physiques, la psyché ne doit-elle pas être autre chose que le corps? Nos psychosomaticiennes et psychosomaticiens ne s'inscrivent-ils pas encore secrètement dans la lignée de Platon et Descartes, alors qu'ils ont rejeté le dualisme depuis belle lurette? Tout comme les libres penseurs qui commencent par séparer - le corps ici, l'âme là - pour mieux se débarrasser ensuite de l'un des éléments.

Peut-être la conception d'Aristote - et de l'Ancien Testament - peut-elle nous aider ici: l'âme en tant que forme vitale du corps dans sa totalité. Que celui-ci soit immortel ou se décompose fait l'objet de débats, même dans la tradition judéo-chrétienne. Mais il existe, même pour les croyants - et plus encore pour ceux qui ne croient pas en une transcendance -, une vie avant la mort. Et il importe de prendre soin de cette forme vitale, cette âme, ici et maintenant. Qu'il s'agisse d'aumôniers responsables s'inscrivant dans une tradition religieuse spécifique, d'oratrices ou de conseillers libres et réfléchis ou de médecins qui consacrent du temps à leurs patients, tous sont des soutiens de l'âme pour des vivants dotés d'une âme. 